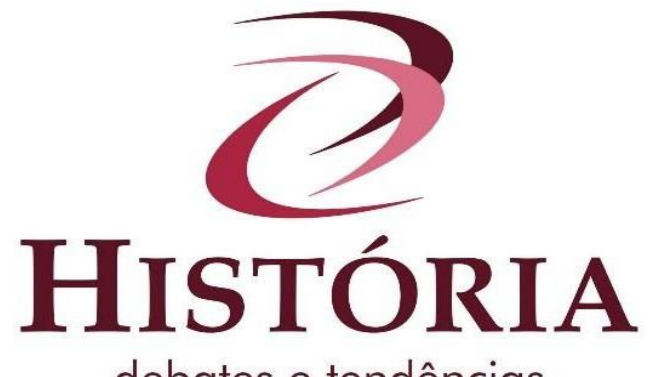

\title{
Necropolítica austral: modernidade, guerra e nação na Argentina do século XIX
}

\author{
Austral necropolitics: modernity, war and nation in nineteenth-century \\ Argentina
}

\section{Necropolítica austral: modernidad, guerra y nación en la Argentina del siglo XIX}

Fabio Feltrin Souza ${ }^{i}$

\begin{abstract}
Resumo: O objetivo deste artigo é analisar a relação entre a noção de biopolítica, a guerra contra o indígena e a constituição nacional da Argentina no século XIX. Para isso, parte-se da concepção foucualtiana, calcada na reflexão da emergência de uma nova tecnologia de governo, a de "fazer viver, deixar morrer", e procura-se cotejá-la e expandi-la com os escritos de Giorgio Agamben e a noção de necropolítica, cunhada por Achille Mbembe, já que é possível identificar, no caso argentino, a constituição de uma máquina de morte que visou, antes de garantir a vida, a destruição material dos corpos e populações humanos julgados como descartáveis e supérfluos. Esta análise terá seu foco na chamada "Conquista do deserto", um ousado plano militar implementado pelo Estado argentino contra os indígenas no pampa.
\end{abstract}

Palavras-chave: Argentina. Conquista do Deserto. Necropolítica

\begin{abstract}
The aim of this paper is to analyze the relationship between the notion of biopolitics, the war against the indigenous and the national constitution of Argentina in the nineteenth century. For this, we start from the Foucualtian conception, based on the reflection of the emergence of a new technology of government, that of "making life, letting die", and we try to compare and expand it with the writings of Giorgio Agamben and the notion of necropolitics, coined by Achille Mbembe, since it is possible to identify, in the Argentine case, the constitution of a death machine that aimed, before guaranteeing life, at the material destruction of human bodies and populations deemed as disposable and superfluous. This analysis will focus on the so-called "Desert Conquest," a bold military plan implemented by the Argentine state against indigenous people in the pampa.
\end{abstract} Keywords: Argentine. Desert Conquest. Necropolitics.

Resumen: El objetivo de este trabajo es analizar la relación entre la noción de biopolítica, la guerra contra los indígenas y la constitución nacional de Argentina en el siglo XIX. Para esto, partimos de la concepción foucualtiana, basada en el reflejo del surgimiento de una nueva tecnología de gobierno, la de "hacer la vida, dejar morir", y tratamos de compararla y expandirla con los escritos de Giorgio Agamben y La noción de necropolítica, acuñada por Achille Mbembe, ya que es posible identificar, en el caso argentino, la constitución de una máquina de muerte que apuntaba, antes de garantizar la vida, a la destrucción material de cuerpos humanos y poblaciones consideradas como 
desechables y superfluas. Este análisis se centrará en la llamada "conquista del desierto", un audaz plan militar implementado por el estado argentino contra los pueblos indígenas de la pampa.

Palabras clave: Argentina. Conquista del Desierto. Necropolitica.

\section{Estado violência}

A nação que emerge a partir dos escritos dos letrados argentinos da geração de 1837 buscou promover a eliminação de todo antagonismo social como forma de garantir a sobrevivência e como elemento constitutivo de suas fronteiras cartográficas. Essa eliminação não se deu apenas com repressão, genocídios físicos, mas também, e antes, no nível discursivo e simbólico. Em outras palavras, coube ao Estado, a partir de um conjunto de tecnologias de promoção da vida e da morte, garantir a implementação do hífen que o une à "nação". Hífen desenhado com o silêncio, o esquecimento e o sangue do que foram considerados danosos, mais especificamente, com a aniquilação dos indígenas na chamada "Conquista do deserto", uma sucessão de campanhas militares orquestradas pelo Estado cujo objetivo era o extermínio das populações autóctones. Esse tipo de política de extermínio das raças, tidas como inferiores, foi estudada por Michel Foucault no curso Em defesa da sociedade, que, em suas páginas finais escreveu que "vocês compreendem então, nessas condições, como e porque os Estados mais assassinos são, ao mesmo tempo, forçosamente, os mais racistas" (1999, p. 309).

As reflexões em torno do Racismo de Estado abriram um vasto itinerário de investigação que permitiram avaliar a quebra do contínuo biológico da chamada "população" e seus efeitos políticos concretos na formação dos Estados-Nacionais Americanos no século XIX. Nesse sentido, o objetivo deste artigo é examinar a relação entre a noção de biopolítica, a guerra contra o indígena e a constituição nacional da Argentina no século XIX. Para isso, parto da concepção foucualtiana, calcada na reflexão da emergência de uma nova tecnologia de governo, a de "fazer viver, deixar morrer", e procuro cotejá-la e expandi-la com os escritos de Giorgio Agamben e a noção de necropolítica, cunhada por Achille Mbembe, já que identifico, no caso argentino, a constituição de uma máquina de morte que visou, antes de garantir a vida, a "destruição material dos corpos e populações humanos julgados como descartáveis e supérfluos" (MBEMBE, 2012, p. 135). A figura do Homo Sacer, como sugere Agamben (2007), cuja vida é definida por sua matabilidade, será fundamental nessa reflexão. Minha hipótese, portanto, é a de que houve um "fazer morrer" que moldou todo discurso nacional 
argentino no século XIX, antes de qualquer implementação de garantia sistemática das vidas que importavam.

O "fazer morrer" moderno: esgaçando o conceito

Para abrir, cortar e analisar o funcionamento do dispositivo nacional na Argentina do século XIX, a noção de biopolítica, seus desdobramentos e variações, parecem ser centrais. Cabe ressaltar que, embora tenha sido Foucault o artífice desse conceito, procuro, na esteira de Edgardo Castro, seguir as "correções" e especulações sugeridas por Giorgio Agamben (CASTRO, 2008, p. 51). O filósofo francês identificou o nascimento da biopolítica num momento histórico bem definido, no qual a vida passa a ser considerada um objeto do poder. Esse poder se caracterizaria pelo direito de vida e morte, isto é, pelo direito de "fazer morrer e deixar viver" e seria exemplificado pela espada do soberano. Dessa forma, o soberano exerceria seu poder sobre a vida do súdito na medida em que pode matá-lo. No entanto, a partir do século XIX há um deslocamento do exercício do poder que Foucault identificou como "fazer viver, deixar morrer". Com esse novo direito, a vida passou a ocupar um lugar central nos destinos da sociedade, ao passo que a morte ocuparia o lugar do privado. Essa ruptura, contudo, não se deu de maneira abrupta, tampouco se manifestou como uma simples sucessão, foi percebida a partir de fatos concretos que se tornaram mais evidentes com o aparecimento das tecnologias disciplinares que tornaram o capitalismo mais rentável, nas políticas de natalidade e mortalidade e no nascimento de uma ciência política (FOUCAULT, 1999).

Enquanto Foucault identifica a inclusão da vida na política apenas na época moderna, para Agamben esse é o fato próprio da política. Na tetralogia Homo Sacer, o filósofo italiano demonstra como a exceção da vida nua, na qual se funda toda política ocidental desde os gregos, é uma relação inclusiva-exclusiva continua. Assim, a soberania, que carrega a estrutura da exceção, incluiria a vida na ordem jurídica por meio de sua exclusão, fato que sempre esteve no centro do poder soberano. Agamben, com isso, demonstrou uma face oculta presente em todo exercício de poder, em todo discurso político e identificou a biopolítica moderna como apenas um dos estágios de sua efetivação (AGAMBEN, 2007).

Para demonstrar sua peculiar concepção de biopolítica, Agamben recorre aos gregos por conta das duas palavras que tinham para vida: zoé e bios. A primeira estaria relacionada à vida meramente natural e a segunda à vida normatizada. Quando Aristóteles busca determinar o que é uma comunidade política cria uma cisão daquilo que se encontraria dentro e fora da polis. Dessa forma, a zoé estaria circunscrita ao âmbito não- 
livre do oikos (casa), ao passo que a vida qualificada estaria caracterizada pela ação livre em vistas a um bem comum. E é somente no espaço comum que o homem pode fazer pleno uso da linguagem (logos) e não simplesmente da voz (phoné), como os seres meramente viventes. Dessa forma, Aristóteles afirmou que apenas na polis as características humanas podem distinguir, através da linguagem, o que é bom e o que é mau, o justo e o injusto. Portanto, desde o início da tradição política do ocidente, a política é pensada a partir de um gesto decisivo entre o mero viver e o viver bem. A comunidade política aristotélica, portanto, se regula através da igualdade e da justiça, na qual o cidadão é um magistrado indefinido que se baseia na superação no mero fato de viver. Essa demarcação, que em certo sentido cria uma distinção entre natureza e cultura, poderia ser entendida como a necessidade da criação de uma lei comum como prerrogativa para instauração da comunidade política. Como somente pode haver polis com o estabelecimento de uma lei reguladora, esta lei estabelece uma diferença entre o que se encontra dentro e o que se encontra fora da polis e só se opera na medida em que exerce essa distinção.

A divisão aristotélica entre zoé e bíos encontraria, séculos mais tarde, paralelo nas teorias contratualistas e é justamente nessa constante fratura que exclui a vida natural que Agamben vai construir sua teoria política. Essa aparente relação de exclusão é na verdade uma relação de exclusão-inclusão, isto é, uma exceptio. E é a partir desse ponto que o filósofo italiano construiu suas análises, na cisão que insere, por exclusão, a vida natural no ordenamento jurídico do Estado, ou seja, ele se detém na exclusão como regra. Por isso afirmou que a exceção soberana é um dispositivo original através do qual o direito se refere à vida e a inclui dentro de si por meio de sua própria suspensão, o que para Agamben é a própria chave da soberania.

Esse paradoxo revela que o soberano está ao mesmo tempo dentro e fora da lei, ou seja, ele valida a lei por sua suspensão. Dessa forma, poder-se-ia afirmar que o soberano, enquanto instituição jurídica, cria, através da linguagem, uma situação normal para aplicar a lei sobre o caos. No entanto, para garantir a aplicação da norma deve-se pressupor esse caos que se encontra fora dela. Por isso o soberano carrega o próprio paradoxo da política, pois, por decretar o estado de exceção, ele estaria, ao mesmo tempo, dentro e fora do ordenamento jurídico. Ele está ali, no limiar entre fato e direito. Assim, a lei se refere a uma exterioridade que Agamben chamou de "relação de exceção", ou seja, uma forma extrema de relação que só inclui algo através de sua exclusão. Exatamente como ocorreu nos discursos fundacionais da nação argentina. Através da linguagem, os 
intelectuais românticos da geração de 1937 criaram uma situação ideal e normal, para isso estabeleceram territórios para os sujeitos-outros, os fora da lei, fora do ordenamento, fora das fronteiras cartográficas que eles mesmos haviam inventado. Para formarem uma identidade nacional, deixaram de fora os indígenas, os gaúchos, os caudilhos, ou seja, as vidas que não mereciam viver. Vidas desprovidas de qualquer regimentalidade, de qualquer garantia legal, pois eram vidas nuas: seus assassinatos não configurariam crime nem perante ao ordenamento jurídico, nem perante à sociedade (AGAMBEN, 2007).

Para Agamben, a biopolítica seria o espaço de politização da vida enquanto mera vida nua entregue ao sacrifício, ao matável, ao descartável e encontra no campo de concentração sua forma mais bem acabada. O campo de concentração é o espaço da exceção, pois escaparia ao direito formal constituído, muito embora não seja uma pura exterioridade em relação ao direito. Por isso, aqueles que são aprisionados nos campos são incluídos no direito, por meio de sua própria exclusão. Se os campos de concentração são espaços nos quais o direito só vale na medida em que instaura a exclusão, então aqueles que ali se encontram estariam desprovidos de qualquer linguagem, de qualquer possibilidade de fala.

Além disso, o campo funcionaria como paradigma e dispositivo, uma vez que ilustra o Estado de exceção na sua relação originária com o soberano, na medida em que a vida nua está na ordem jurídica e permite diagnosticar como toda política funciona a partir das mesmas premissas que o tornaram possível. A partir desse ponto, ele argumenta que o espaço político contemporâneo não é mais a cidade idealizada, a polis erguida pela racionalidade da lei e da norma, mas o campo de concentração, cuja marca é a ausência de lei, a anomia, onde a zoé se transforma em bios. No lugar do cidadão, o homo sacer, pois os habitantes foram despojados de todo estatuto político e reduzidos a vida nua. Por isso, seguindo Agamben, não seria forçoso sugerir que, levando ao limite o conceito de exceção como regra da política e que o fora da lei está dentro desse discurso por sua necessária exclusão fundante, a nação, e no caso desta reflexão o espaço chamado de "deserto", comunga dos mesmos pressupostos que o campo de concentração. Os indígenas, argentinos estariam, nos textos dos intelectuais de 1837, no mesmo espaço jurídico-discursivo que judeus e mulçumanos no campo de concentração nazista. E é justamente aí que reside o paradoxo: ao mesmo tempo em que eles estão fora da nação, por não serem desejados, são partícipes de uma internalidade ficcional, visto que o "nós" só é possível ser dito quando o "outro" tem uma fisionomia bem definida. Dessa forma, a exclusão é a regra da criação de uma nação. Essa relação é o 
que Jacques Derrida chamou de brisura, de juntura, em que a exclusão vem acompanhada de um hífen que a une a inclusão (DERRIDA, 1999). A fronteira da nação, enquanto discurso, seria um limiar, uma zona de indeterminação onde não podemos definir o que está dentro e o que está fora dela, pois todos os sujeitos e conteúdos estão dentro-fora, incluídos-excluídos, pois um depende do outro para existir. A posição que um ocupa nesse discurso é alicerçada pelo outro.

Entretanto, conforme pondera Berenice Bento, nem todas as vidas são vidas nuas, como pensa Agamben (BENTO, 2018). Umas nascem para viver, enquanto outras têm sua matabilidade inscrita na diferença da norma nacional, ou seja, o homo sacer descreve a fisionomia de grupos específicos cuja vida não merece e não deve ser vivida. $\mathrm{Na}$ constituição do Estado-Nacional argentino é possível identificar as violências, as aporias e os paradoxos insolúveis da nação, na medida em que ela é um arquivo contaminado por sua impureza fundamental. Zygmunt Bauman afirmou que "toda aposta na pureza produz sujeira e que toda aposta na ordem cria monstros" (BAUMAN, 2004). A maquinaria moderna do "fazer morrer", típicas dos Estados-nação americanos, ao privilegiarem a civilização, a modernidade e a vida, em última estância, compuseram as justificativas para guerras e extermínios:

\begin{abstract}
As guerras já não se travam em nome do soberano a ser defendido; travam-se em nome da existência de todos; populações inteiras são levadas à destruição mútua em nome da necessidade de viver. Os massacres se tornaram vitais. Foi como gestores da vida e da sobrevivência dos corpos e da raça que tantos regimes puderam travar tantas guerras, causando a morte de tantos homens. E, por uma reviravolta que permite fechar o círculo, quanto mais a tecnologia das guerras voltou-se para a destruição exaustiva, tanto mais as decisões que as iniciam e encerram se ordenaram em função da questão nua e crua da sobrevivência (FOUCAULT, 1999, p. 129).
\end{abstract}

É nesse sentido que o exame dos modos de constituição das nações na América Latina, em especial a Argentina, junto à noção de biopolítica, é fundamental mobilizar as concepções de tanatopolítica, ou necropolítica, como tem sugerido Achille Mbembe em chave pós-colonial. Assim, na esteira do argumento de Bento, sustento que, para real efetivação da governabilidade, as táticas e técnicas do "fazer viver", é necessária a produção de zonas de morte. Ou seja, "governabilidade e poder soberano não são formas distintas de poder, mas têm (...) uma relação de dependência contínua - seja numa abordagem sincrônica ou diacrônica" (BENTO, 2018). Por isso, não bastaria, como argumenta Michel Foucault em Em defesa da sociedade, que as mortes oriundas das 
táticas do "fazer viver, deixar morrer" estariam na lógica da preservação da vida, já que o verbo "fazer" sugere que o Estado não irá desenvolver políticas de morte. Antes de criar ações concatenadas de preservação da vida, o Estado argentino teria criado uma política de eliminação sistemática dos indígenas, um necropoder, portanto.

\section{Guerra das raças: extermínio e nação}

Desde a independência, as elites letradas portenhas buscavam alternativas para o chamado vazio de civilização e de população que tomava conta da Argentina. A região dos pampas, chamada de deserto, deveria ser preenchida, eliminando, assim, aquilo que consideravam ser as mazelas da nascente nação. A imigração de europeus era entendida como a melhor das soluções para a "poblacion maldita", para a tradição espanhola (entendida como um antigo regime aos moldes do que ocorrera na França) e para inadequação da raça.

$\mathrm{Na}$ teoria evolucionista de Spencer, a questão da "raça" figurou como um dos elementos centrais e passou a ocupar um lugar de destaque no pensamento social latinoamericano. Charles Hale identifica duas fontes de racismo europeu, ambas aplicáveis à América Latina, e que ganharam grande força no final do século XIX: a primeira, centrada no argumento antropológico, reunia as reações das sociedades européias frente ao contato com outros povos durante o processo de expansão e colonização. Nele, determinavam que apenas certas "raças" seriam capazes de atingir a civilização, por causa de sua maior aptidão para se adaptar aos desafios da sobrevivência. Esse darwinismo social, presente em Spencer e outros evolucionistas, teve grande impacto nos pensadores latinoamericanos, como em Sarmiento e Alberdi, por exemplo. Em outro sentido, a ideia de "raça" significava a nacionalidade no sentido clássico, ou seja, as pessoas que, ao longo de uma história comum, desenvolviam peculiaridades linguísticas, religiosas e culturais em um contexto geográfico, como fez Sarmiento, em Facundo (HALE, 2000, p. 2). Seguindo outro filósofo fundamental para o esquema argumentativo da guerra das raças na Argentina, Hippolyte Taine, Sarmiento preocupa-se com a necessidade de encontrar a verdadeira psicologia de um povo:

el historiador como científico debía buscar el 'estado moral elemental' o 'psicología' de un pueblo, estado que se encuentra debajo de la superficie de los artefactos humanos. El hombre visible o externo en la historia revela un hombre invisible o interno. Esta psicología es fruto de la acción de tres 'fuerzas primordiales': le race, le millieu, et le moment. En el esquema 
histórico de Taine, la raza (definida como 'tendencias innatas y hereditarias' ligadas normalmente a 'diferencias acusadas de temperamento y estructura corporal') era sólo un elemento determinante (SARMIENTO, 2001, p. 129).

Em seu exilo chileno, Juan Bautista Alberdi produziu o que talvez sejam suas obras mais significativas sobre as formulações do que deveria ser a Argenina: Acción de la Europa en América, de 1842, e Bases y puntos de partida para la organización de la República Argentina. Imagina em ambas uma Arché fundante capaz de introduzir o país na corrente da modernidade. Para efetivação desse projeto seria preciso não só criar hábitos civilizados, como também instituir o poder em todo território. Nesses textos Alberdi desacredita na capacidade da população autóctone, gauchos e sobretudo indígenas, em desenvolver esses hábitos e cria a imagem de um país vazio de civilização. Para suprir essa cartografia indomável seria preciso mais que importar hábitos europeus; era preciso incentivar a imigração e eliminar todos indígenas. Para o argentino, cada imigrante desejado traria mais civilização inscrita no corpo e nos hábitos, do que a maioria dos livros e manuais. Ao privilegiar os hábitos em detrimento de um projeto educacional, nos moldes daquele defendido por Sarmiento, Alberdi mostra uma característica que jamais perderia nos anos de vida pública: sua marca anti-intelectualista. Para ele, os costumes não são modificados através da instituição letrada formal, mas sim a partir do contato com outros hábitos realmente existentes, segundo a lógica de Rousseau da educação pelas coisas. Alberdi confiava na pedagogia das coisas, nos civilizados hábitos dos estrangeiros europeus para fundar um novo ethos, uma nova configuração dos sujeitos e, assim, regenerar e salvar a nação das garras da barbárie. Para que o transplante imigratório fosse exitoso, seria preciso adequação das leis, propondo aos imigrantes dupla nacionalidade, liberdade de culto, vantajosos tratados com a Europa, estradas de ferro, livre navegação e liberdade comercial (TERAN, 2008).

Sarmiento também tratou com bastante vigor deste tema. Nas páginas finais de seu Facundo, o argentino escreveu que "el elemento principal del orden y moralización que la República Argentina cuenta hoy, es la imigración europea" (SARMIENTO, 1977, p. 159). Pouco mais de um ano após terminar a escrita de Facundo, Sarmiento parte para Europa a fim de realizar o grande sonho de colocar seus pés no requintado solo do velho continente. Seu primeiro destino foi a Prússia onde teve contato com os românticos germânicos. Com eles aprendeu que "la raza alemana" seria historicamente migrante, o que lhe causou otimismo, pois aquele povo seria muito bem-vindo em terras americanas. Os autores alemães, segundo Sarmiento, reconheciam que a imigração de seus 
compatriotas seria inevitável (SARMIENTO, 1993, p. 232). Em Viajes, ele chega a propor uma política oficial para atrair alemães para a América do Sul, na qual os governos deveriam subsidiar as viagens, a instalação, a compra de ferramentas e assegurar terras aos recém-chegados. Como era típico de Sarmiento, chegou a dar detalhes de como deveriam funcionar os postos de informação.

Para os dois argentinos, cada europeu que aportasse em terras americanas traria fragmentos de civilização em seus hábitos e logo essas sementes iriam florir e comunicar a todos os outros habitantes. Trazer os "pedazos vivos" de civilização significaria mudar a estrutura étnica do país e só assim conduzi-la a um novo amanhecer (ALBERDI, 1969, p. 250). Para a concretização dessa legítima importação seria preciso, segundo Alberdi, criar as condições constitucionais para vinda de europeus e norte-americanos. Para isso, as leis sobre aquisição de terras, direitos civis e religião deveriam ser alteradas. Destes, a religião parecia ser o mais controverso e complicado a se tratar no alvorecer da nação. Se tomarmos os escritos de alguns letrados daquele período, poderemos perceber que havia uma certa precaução com esse tema, talvez porque a memória dos contratempos que o presidente Rivadavia teve com o clero e a hierarquia católica, por conta de sua hostilidade, ainda estivesse presente.

\section{O espaço do "fazer morrer"}

Durante o século XIX a paisagem do pampa constituiu uma unidade dramática com tudo que se desenvolvia ali. Alvo de todo um conjunto de discursividades, o deserto foi uma das principais preocupações do romantismo literário. No poema La cautiva, Esteban Echeverría constrói as imagens da barbárie, da falta, do grande oceano em terra a ser domado, da violência, do pampa, do indígena, do nomadismo a ser combatido. Tratase da épica história dos raptos de Maria e Brián. A dicotomia civilização e barbárie estava presente na condição de heroína construída para Maria, enquanto os índios são o oposto da humanidade. O drama construído pelo poeta deveria, necessariamente, ser superado pelo curso da história. Para os românticos do Prata, o pampa era um grande vazio geográfico e cultural. Um problema a ser enfrentado pelos condutores da barca-nação em direção ao futuro.

As imagens lapidadas pela pluma do poeta ganham contornos plásticos na série de quadros de Johann Moritz Rugendas. O viajante alemão ficou particularmente seduzido pela obra de Echeverría, como confessou em inúmeras cartas trocadas com a chilena 
Carmen Ariagada (DINNER; COSTA, 1999, p. 23). Quando Rugendas chegou a Montevidéu em princípios de 1845, já havia entrado em contato com o poema de Echeverría. Provavelmente isso tenha se dado através de Sarmiento que havia recebido um esboço do poema quando estava no Chile. Rugendas iria conversar com Echeverria no mês de julho daquele ano, quando regressou a Montevidéu, já em viagem para o Rio de Janeiro (seu destino final na América antes de regressar em definitivo para Europa). Na capital do Império o viajante promoveu uma exposição na Academia de Belas Artes e, sob a mediação de Nicolas-Antoine Taunay, conheceu o imperador, a quem presenteou com uma das versões do Rapto de la cautiva, já sob influência de Echeverría, quando passou a conceber a paisagem para depois inserir os personagens que dariam o suporte a ela. Essa construção visual mereceu destaque em uma das cartas de Sarmiento, escrita ainda no Rio de Janeiro:

\begin{abstract}
La pampa infinita y los celajes del cielo por fondo, confundidos en parte por las nubes del polvo que levantan los caballos médios domados que monta el salvaje; la melena desgreñada flotando al aire, y sus cobrizos brazos asiendo la blanca y pálida víctima, que prepara para su lascívia. Ropajes flotantes que se prestan a todas las exigências del arte; grupos de ginetes y caballos; cuerpos desnudos; pasiones violentas, contrastes de caracteres en las razas, de trajes en la civilización de la víctima y la barbárie de raptor, todo ha encontrado en Rugendas, en este asunto de su animoso pincel (SARMIENTO, 1977, p. 74).
\end{abstract}

Na sua radiografia do pampa, Sarmiento apresenta uma cartografia desse vazio; um vazio de sentido, de civilização, como em La Cautiva, de seu colega Esteban Echeverría. Como apontam Carlos Altamirano e Beatriz Sarlo, aí uma clara referência a Montesquieu que havia localizado nesse cenário nas planícies desérticas e "vazias" da Ásia, o espaço propício para o aparecimento da barbárie (ALTAMIRANDO \& SARLO, 1997, p. 89). Assim, é possível constatar o que podemos chamar de um arquivo orientalista em Facundo (SOUZA, 2012). O meio inóspito, o oceano em terra é assim desenhado por Sarmiento:

Imagina una extensión de dos mil léguas cuadradas, cubierta toda de población pero colocadas las habitaciones a cuatro leguas de distancia unas de otras (...) la sociedad ha desaparecido completamente; queda solo la família feudal aislada, reconcentrada, y no habiendo sociedad reunida, toda clase de gobierno se hace imposible. Ignoro se el mundo moderno presenta un gênero de asociación tan monstruoso como éste (SARMIENTO, 1977, p. 61). 
Para Sarmiento, o signo da barbárie guardaria laços íntimos com o oriente, não só porque acreditava na similitude geográfica geradora de hábitos condizentes com a paisagem, como também porque a história da razão iluminista, esteira na qual enquadrava suas análises, promovia uma separação entre os povos orientais e ocidentais. A referência ao oriente e à figura do déspota oriental carrega uma dupla função: a de imprimir uma ideia geral do bárbaro, assinalando o traço constitutivo do Outro como diferença cultural; e a de apresentação da ideia de despotismo, essa maneira de governo autocrática tão criticada pelo argentino. Essas concepções eram, de maneira geral, partilhadas letrados de 1837.

O orientalismo pode ser lido como um recurso estético tipicamente romântico, utilizado por Sarmiento para trazer à cena, sociedades desconhecidas no chamado mundo ocidental. O arquivo orientalista, como o chamo, formaria, portanto, parte da bagagem européia a qual o letrado argentino estava ligado. $\mathrm{O}$ oriente lhe chegava não só pelas referências literárias de Volney e Victor Hugo (SARMIENTO 1977, p.49), ou por sua viagem à Argélia durante seu exílio, como também pelas próprias concepções de filosofia da história que circulavam pelo século XIX. Nessa filosofia da história de base hegeliana, o oriente é o próprio despotismo, pois esses povos não conheceriam a democracia e viveriam sob a égide de um chefe absoluto e de códigos de moralidades característicos de uma condição nômade:

La tribu árabe que vaga por las soledades asiáticas, vive reunida bajo el mando de un anciano de la tribu o un jefe guerrero; la sociedad existe aunque no esté fijada en un punto determinado de la tierra; las creencias religiosas, las tradiciones inmemoriales, la invariabilidad de las costumbres, el respeto a los ancianos, forman, reunidos, un código de prácticas de gobierno, que mantiene la moral, tal como la comprenden el orden y la asociación de la tribu (SARMIENTO 1977, p. 49).

Nesse enredo, o deserto seria a impossibilidade de qualquer ordenamento e a origem da barbárie. É contra esse ordenamento imagético, é contra essa cena, que Sarmiento investia toda sua violência argumentativa. O país de paisagem inóspita só poderia gerar seres como os indígenas e os gaúchos. Este problema é discutido visualmente por Olascoaga em sua litogravura. Além da paisagem alongada e horizontal, criando a sensação de vastidão e vazio, a imagem é composta por um grupo de indígenas em movimento e um conjunto de ossadas no primeiro plano. De maneira enfática, o que acaba por ser salientado na imagem é uma característica precisa da percepção do espaço como um "vazio" absoluto. 


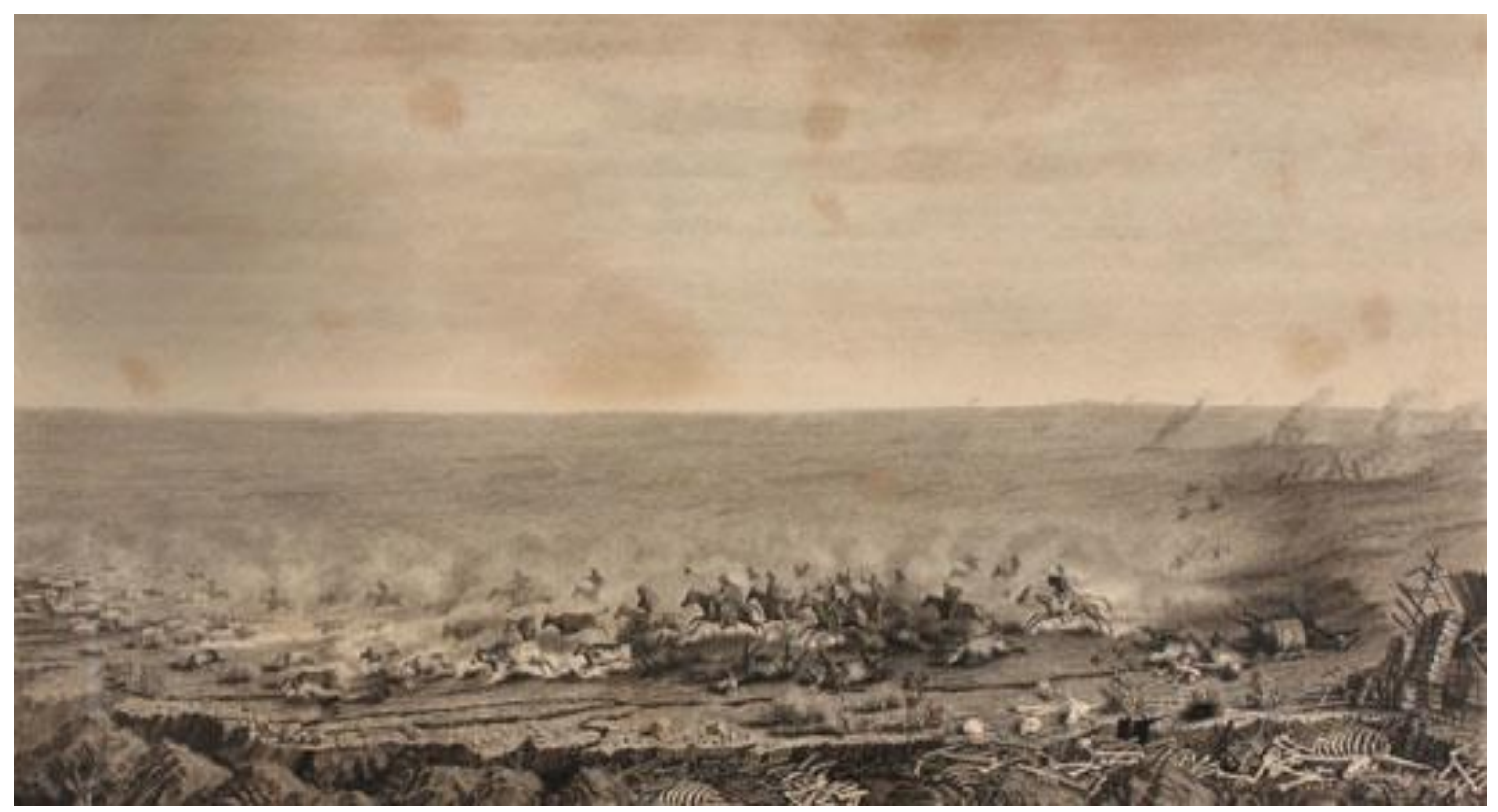

Imagem 1 - Manuel Olascoaga, La pampa antes de 1879. Litogravura. Fonte: MARTINEZ ESTRADA, Ezequiel. Radiografia de la pampa. Buenos Aires: Losada, 1974.

As ossadas, dispostas em primeiro plano, eram utilizadas como fundamento na construção do pampa como deserto e, por conseguinte, como espaço da barbárie e da morte, além de marcarem uma longa e sangrenta guerra. A terra dos indígenas, desconhecedores do conjunto de regramentos e limites típicos de uma sociedade civilizada, era, na ótica dos europeus e membros das elites portenhas, o espaço próprio do horror. Cuidadosamente nominada de La pampa antes de 1879, a imagem faz referência ao período anterior à conquista empreendia pelo general Julio Argentino Roca e, consequentemente, aponta para a convicção de que a Argentina estava em marcha para um futuro redentor, moderno e civilizado, já que o pampa deixava de ser o território do inimigo. Assim, noções como deserto, por exemplo, não significam exatamente um lugar específico, natural, passível de ser delimitado geograficamente, mas antes, uma imagem associada a um tipo de experiência social, cultural e econômica; uma imagem inventada, portanto. É nesse sentido que se pode afirmar que há uma construção cultural da paisagem, na medida em que ela foi imaginada. Quando essa imaginação ganha concretude, ela mistura categorias e torna-se mais real que seu referente. Há um conjunto de imagens (literárias e artísticas) que compõem o que suspeitamos ser uma ordem visual que transformou o pampa em deserto, em espaço de morte a partir da politização da vida. A construção dessas tipologias ganhou condição de verdade na Argentina do século XIX e como afirmaram e Martinez-Pinzón e Uriarte: 
La máquina de guerra crea el mismo espacio que busca consuistar. Es el caso de desierto en los últimos años del siglo XIX en varios países sudamericanos. Hacerle la guerra al desierto ideológico y ficcional sobre el que escribían las elites no fue otra cosa que generar un desierto concreto y absoluto (MARTINEZ-PINZÓN \& URIARTE, 2016, p. 12).

A instauração desse enredo discursivo foi fundamental para que a matabilidade dos corpos indígenas mediante a guerra não se configurasse um crime, mas, ao contrário, uma positividade. Suponho, portanto, como esse genocídio foi legitimado através da invenção e mobilização de um conjunto de imagens e levado a cabo pela máquina de guerra da modernidade em seu afã classificador, ordenador, normatizador e necropolítico. Por isso, seguindo Michel Foucault, Achile Mbembe e Giorgio Agamben, não seria forçoso sugerir que, levando ao limite o conceito de exceção como regra da política e que o fora da lei está dentro desse discurso por sua necessária exclusão fundante, os discursos nacionais, cuja marca temporal está organizada na distância entre espaço de experiência e horizonte de expectativas (KOSELLECK, 2006), comungariam desses mesmos pressupostos. Os indígenas estariam, para as elites argentinas, sob o estatuto jurídicodiscursivo de exclusão e matabildiade autorizadas (SOUZA, 2015). E é justamente aí que reside o paradoxo: ao mesmo tempo em que eles estão fora da nação, por não serem desejados, são partícipes de um internalidade ficcional, visto que o "nós" só é possível de ser dito quando o "outro" tem uma fisionomia muito bem definida. A posição que um ocupa nesse discurso é alicerçada pelo outro, sobretudo quando personagens da "conquista do deserto", como Estanislao Zeballos, que colecionava crânios indígenas com o fito de analisá-los à luz da frenologia e da antropometria, afirmavam que o lugar desses indígenas seria o museu, pois estariam fora do tempo e atrasados na marcha da História da Humanidade (Geschichte).

É desse modo que a partir de 1870 abriu-se uma nova etapa na guerra contra o índio, uma vez que o Estado argentino decidiu adotar uma espécie de "solução final", como sugeriu Zeballos, para o problema indígena, ou seja, buscaram sua eliminação física (VIÑAS, 1982). Essa opção não foi resultado apenas das novas possibilidades tecnológicas, oferecidas pelas modernas tecnologias militares, mas fundamentalmente foi construída no âmbito discursivo através de numerosas estratégias necropolíticas. Curiosamente, a chamada conquista do deserto, levada a cabo pelo general Julio Argentino Roca, e futuro presidente, foi acompanhada não apenas pelo exército argentino, mas também por religiosos, cientistas, artistas e fotógrafos. Em 1879, as colunas do exército argentino avançaram da extensa linha de fronteira com os índios até o Rio Negro, 
transformando-se no gesto mais espetacular de um conflito armado que continuaria até 1885. Tal evento, nos confirma Viñas (1982), foi o desfecho de uma história de barbárie contra os habitantes nativos do Pampa. Como forma de celebrar esse triunfo, o pintor uruguaio Juan Manuel Blanes recebeu a incumbência de pintar a glória do general Roca. Pintada em grandes proporções e fortemente embasada nos documentos disponíveis sobre a conquista do deserto, Blanes repete o sentido horizontal a criar a sensação de vastidão. Entretanto, o conteúdo principal não é mais o drama da barbárie indígena ou do deserto indomável, é, ao contrário, preenchido em primeiro plano pelos oficiais de Roca, postados de maneira vitoriosa e apresentando uma sutil particularidade: o ponto de vista para a composição é próximo e alto, como uma célebre fotografia de Antonio Pozzo, de modo que apenas as cabeças dos oficias fiquem acima da linha do horizonte. Ora, diante de tudo que enfatizamos, não seria forçoso afirmar que a imagem criada por Blanes celebra o triunfo da racionalidade, simbolizada pelas cabeças, que haviam domado aquela terra infinita. Tal argumento parece ganhar corpo se observamos que à direita do quadro estão marinheiros, cientistas e fotógrafos e à esquerda, religiosos acompanham indígenas catequizados e "domesticados" (MALOSETTI COSTA \& PENHOS, 1991). Esta composição parece pertencer a um típico sistema de exclusão baseado numa vontade de verdade e apoiada sobre o suporte não apenas do Estado, mas de toda institucionalidade legitimada na e pela sociedade, como sustentei anteriormente. Ademais, diferente de todo conjunto visual elaborado sobre a conquista do deserto (SOUZA, 2015), construído sob o signo do movimento, da ação, enfatizando, em muitos casos, o nomadismo indígena (que partia de lugar nenhum e em direção desconhecido), a imagem lapidada por Blanes é estática, enraizada e celebra, pelo imperativo da força, o hífen a promover a junção entre Estado e Nação. 


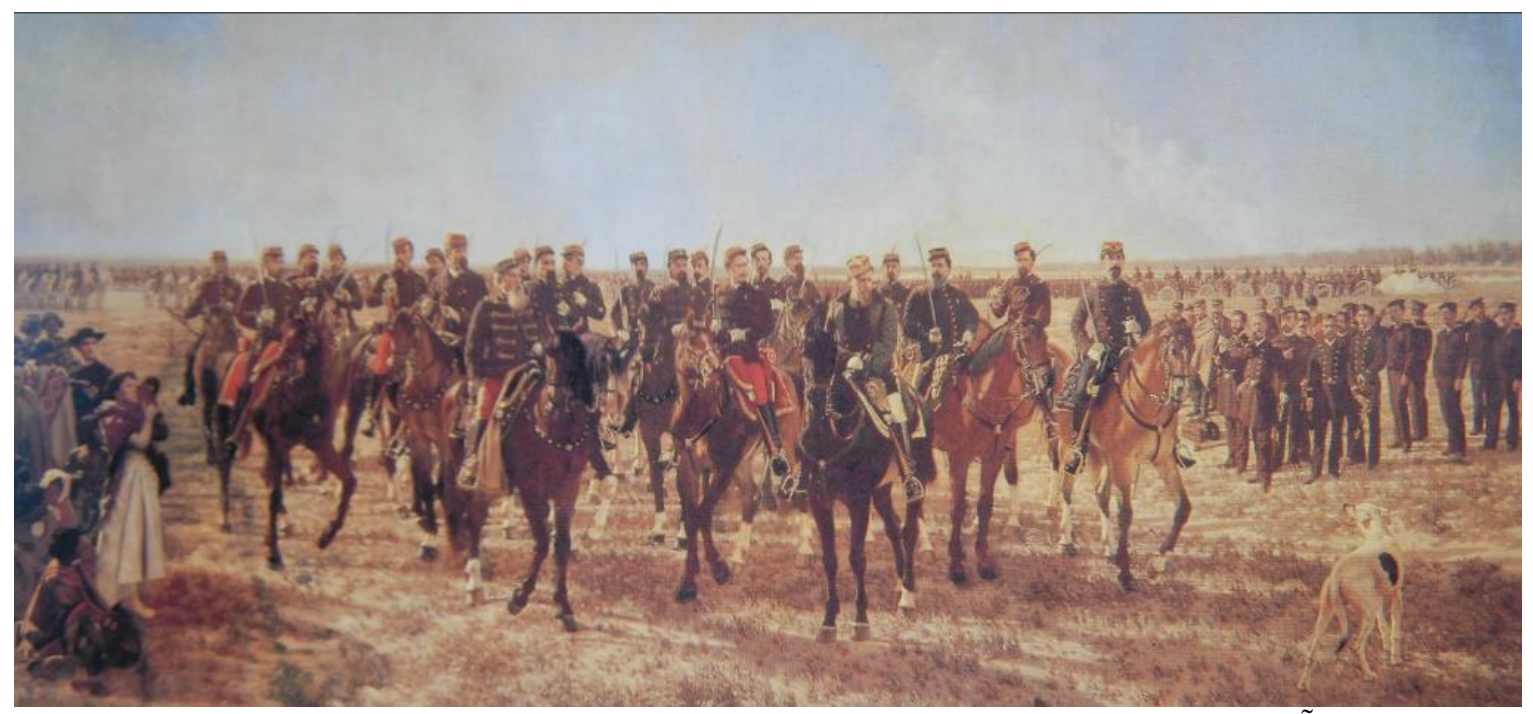

Imagem 2 - Juan Manuel Blanes, La Revista del Río Negro, 1894. FERNANDEZ SALDAÑA, Jose Maria. Juan Manuel Blanes, su vida y sus cuadros. Montevideo: Imprensa Uruguaya, 1931.

É possível perceber uma intensa mobilização de imagens geográficas para a produção de uma narrativa dramática de modo a justificar a eliminação física e simbólica das populações indesejadas na moldura nacional. Como resultado desta necropolítica, muitos indígenas (famílias e grupos inteiros) foram mortos, sequestrados e detidos em campos de disciplinamento, como o que funcionou na ilha de Martin Garcia, entre 1870 e 1890, onde milhares de nativos foram mantidos em cativeiro e forçados a realizar trabalhos na ilha (em Carmen da Patagônia, Junín de los Andes, Chinchinales e Valcheta também funcionaram campos semelhantes). Nestas investidas, mulheres e crianças foram vendidos para servir como empregados nas casas de família em Buenos Aires, enquanto os homens jovens e adultos foram incorporados às Forças Armadas. Já outros contingentes populacionais foram incorporados às plantações de açúcar em Tucumán (URIARTE, 2010). Além disso, os caciques Tehuelches Inacayal e Foyel foram presos com suas famílias no Museu de Ciências Naturais de La Plata, a pedido de seu diretor, Francisco Moreno, pois, como já dito, eles seriam sombras de um passado que não reconhecia seu lugar.

\section{Extremidades e limiares: onde habita a biopolítica}

O fim último da nação, a soleira que marca uma linha divisória, não será lida em seu finis, como gostaria o discurso que busca a "Identidade", a essência da Nação, a Verdade nas coisas, mas, inexoravelmente, a partir do com. Assim, pode-se desarmar essa 
instituição, esse nome próprio da violência (DERRIDA, 2007). Para isso é preciso cortá-la e, a partir desses fragmentos, analisar os traços que construíram uma imagem de interioridade e homogeneidade. As bases dessa imagem estão apoiadas na idéia de lugar, estância em que as coisas teriam suas origens. Dessa forma, em consonância com Raul Antelo, que seguindo Aristóteles, é preciso ler esse "lugar" como topos, pois ele não é matéria, nem forma, nem princípio ou fim do movimento (ANTELO, 2008). O topos é um limiar, um confim que proporciona encontros, onde os discursos são escavados e ganham vida no contato com as ausências, com as sombras. O lugar é, pois, essa extremidade da qual me referia, onde as coisas efetivamente acontecem. Pensar a extremidade como topos ou confim é a possibilidade de rearmar a emergência desses discursos no momento em que as verdades ainda não tinham status epistemológico de verdade; impugnando, portanto, sua solidez, sua monumentalização. Por isso, Raul Antelo recolhe de Jacques Lacan a noção de extimidade, pois ela carrega o signo de incompletude no plano simbólico e anuncia de maneira absolutamente problemática a presença do real na história. Esse conceito foi concebido a partir do termo intimidade e pode oferecer uma alternativa àquilo que venho tratando como interior-exterior ou dentro-fora. Extimidade permite supor que o mais íntimo encontra-se, paradoxalmente, no exterior de maneira exposta e aberta. São, pois, topologias que vacilam entre o exterior e o interior e não espaços marcados e demarcados (ANTELO, 2009).

No paradoxo lugar de imaginar a nação, o espaço-tempo da pátria, sustenta o espaço-tempo do estado a partir de metáforas políticas. A pátria é um modelo original, nela estão as tradições, o passado, a infância, o lar. Uma das funções do discurso letrado seria recorrer a esse modelo e transformá-lo em um centro legitimador do futuro, pois a pátria é uma singularidade a concentrar a totalidade de uma cena ideal a delinear a reconstrução do mundo. Essa cenografia articula a marcha da formação de modelos para um país do amanhã, a definir um diagrama da formação de uma ordem sobre o espaço vazio do deserto. Nesse jogo utópico que congrega realização da história, especulação filosófica e uma arquitetura política, dois fatores seriam essenciais para formação nacional: a ocupação do espaço vazio, lido e sentido como deserto geográfico, civilizacional e histórico; a ocupação desse espaço perfila um sistema de ralações sociais desejáveis, instituições estatais e expressões culturais alinhadas com o pensamento dito ilustrado. Nesse jogo de ecos e plenitudes, de ausências e descentramentos exteriores, a 
escritura política e literária satura o vazio histórico e propõe saídas para superar a desilusão com o presente.

A herança desses primeiros românticos, catalisadores dos primeiros discursos nacionais, pode ser traduzida como uma máquina de guerra, como uma maquinaria a introduzir a zoé na polis, ou seja, a violência amparada e legitimada pela lei. Essa herança não trouxe cidadania ou amparo ao conjunto mais amplo da sociedade. Foi, no entanto, uma produtora de Homo Sacer's, de sujeitos sem qualquer direito à vida. O "sol de Mayo", o sol da razão que regeneraria o povo, fora pintando com o sangue daqueles que os monumentos de cultura esmagaram. A racionalidade da biopolítica como forma de governo, foi antecipada pela necropolítica, ou seja, pelo "fazer morrer" sistemático daqueles cuja humanidade fora esvaziada por aquilo que poderíamos chamar de dispositivo nacional, ou seja, uma política de inimizade (MBEMBE, 2017).

\section{Referências bibliográficas}

AGAMBEN, Giorgio. Homo sacer: o poder soberano e á vida nua I. Belo Horizonte: Humanitas, 2007.

ALBERDI, Juan Bautista. Bases e pontos de partida para a organização política da República Argentina. Rio de Janeiro: Imprensa Nacional, 1941.

Obras selecionadas. Tomo I. Buenos Aires: Librería de la Facultad, 1920.

ALTAMIRANO, Carlos \& SARLO, Beatriz. Ensayos Argentinos: de Sarmiento a la vanguardia. Buenos Aires: Ariel, 1997.

ANTELO, Raul. Lindes, limites, limiares. In: Boletim de Pesquisa - NELIC: Edição Especial, vol.1 - Lindes / Fronteiras (2008).

Subjetividade, Extimidade. In: Boletim de pesquisa - NELIC. v. 9, $\mathrm{n}^{\circ} 14$, Florianópolis, 2009.

BENTO, Berenice. Necrobiopoder: quem habita o Estado-nação. In: Cadernos de Pagu, 53, 2018.

BAUMAN, Zygmunt. Amor líquido: Sobre a fragilidade dos laços humanos. Rio de Janeiro, Jorge Zahar, 2004.

CASTRO, Edgardo. Giorgio Agamben: uma arqueologia de la potência. Buenos Aires/San Martin: UNSAM Edita, 2008.

COSTA, Laura Malosetti. El Rapto de la Cautiva: un tema de encuadre de la plástica rioplatense. In: II Jornadas de teoria e historia de las artes: articulación del discurso escrito com la producción artística en Argentina y Latinoamerica, siglos XIX y XX.

Buenos Aires, CAIA-Contrapunto, 1990.

DERRIDA, Jacques. Gramatologia. São Paulo: Perspectiva, 1999. 
2007.

. Força de lei: o fundamento místico da autoridade. São Paulo: Martins Fontes,

DIENER, Pablo \& COSTA, Maria de Fátima. A América de Rugendas: obras e documentos. São Paulo: Livraria Kosmos Editora, 1999.

ECHEVERRÍA, Esteban. Obras Escogidas. Caracas: Biblioteca Ayacucho, 1991.

. La Cautiva. Buenos Aires: Bureau Editor, 2005.

FOUCAULT, Michel. Em defesa da sociedade: curso no Collège de France (19751976). São Paulo: Martins Fontes, 1999.

1999.

. História da sexualidade: a vontade de saber. Vol 1. Rio de Janeiro: Graal,

HALE, Charles. Ideas políticas y sociales en América Latina, 1870-1930. In: BETHELL, Leslie (ORG). Historia de América Latina. 8. América Latina: cultura y sociedad, 18301930. Barcelona: Crítica, 2000.

KOSELLECK, Reinhart. Futuro Passado: contribuição à semântica dos tempos históricos. Rio de Janeiro: Contraponto, Editora Puc-RJ, 2006.

MARTINEZ-PINZÓN, Felipe; URIARTE, Javier. Entre el humo e la niebla: guerra e cultura en América Latina. Pittsburg: University Press, 2016.

MBEMBE, Achille. Necropolítica: seguido de sobre el governo privado indirecto. Santa Cruz de Tenerife, Melusina, 2011.

. Crítica da razão negra. Portugal, Antígona, 2014.

SARMIENTO, Domingo Faustino. Facundo: civilizacion y barbarie. Venezuela: Ayacucho, 1977.

. Viajes por Europa, África y América (1845 - 1847). Buenos Aires/Paris:

ALLCA XX/UNESCO, 1993.

Conflicto y armonías de las razas en América. In: Obras completas, XXXVII.

Buenos Aires: Universidad Nacional de La Matanza, 2001.

SOUZA, Fábio Feltrin de. Espectografias da Nação: o 'eu' e o 'outro' no discurso fundacional da Argentina. In: Maria Bernadete Ramos Flores; Patrícia Peterle. (Org.). História e Arte: Imagem e Memória. 1aed.Campinas: Mercado das Letras, 2012.

O pampa argentino e a conquista do deserto: uma relação discursiva.

Dimensões - Revista de História da UFES, 2015.

TERAN, Oscar. Historia de las ideas en la Argentina: Diez lecciones iniciales, 1810-1980. Buenos Aires: Siglo Veintiuno, 2008.

URIARTE, Javier. Viagem, guerra e consolidação nacional: as reminiscências do "perito" Moreno. Floema, ano VI, n. 6, p. 106-130, 2010.

VIÑAS, David. Indios, ejercito y frontera. Buenos Aires: Siglo XXI, 1982. 
Submetido em: 13/10/2019

Aprovado em: 22/06/2020

Publicado: 23/09/2020

\footnotetext{
' É mestre e doutor em História Cultural pela Universidade Federal de Santa Catarina (UFSC). É professor associado do Curso de História da Universidade Federal da Fronteira Sul (UFFS - Erechim) e do "Programa de Pós-Graduação Interdisciplinar em Ciências Humanas" (PPGICH) email fabio.feltrin81@ gmail.com
} 